\title{
Conformation and Catalytic Properties Studies of Candida rugosa Lip7 via Enantioselective Esterification of Ibuprofen in Organic Solvents and Ionic Liquids
}

\author{
Xiang Li, Shuangshuang Huang, Li Xu, and Yunjun Yan \\ Key Laboratory of Molecular Biophysics of the Ministry of Education, College of Life Science and Technology, \\ Huazhong University of Science and Technology, Wuhan 430074, China
}

Correspondence should be addressed to Li Xu; xuli@hust.edu.cn and Yunjun Yan; yanyunjun@hust.edu.cn

Received 30 September 2013; Accepted 23 October 2013

Academic Editors: A. A. Iglesias and A. Surguchov

Copyright (C) 2013 Xiang Li et al. This is an open access article distributed under the Creative Commons Attribution License, which permits unrestricted use, distribution, and reproduction in any medium, provided the original work is properly cited.

\begin{abstract}
Enantioselective esterification of ibuprofen was conducted to evaluate the enzyme activity and ees of lipase from Candida rugosa (CRL7) in ten conventional organic solvents and three ionic liquids. Different alcohols were tested for selecting the most suitable acyl acceptor due to the fact that the structure of alcohols (branch and length of carbon chains; location of -OH functional group) could affect the enzyme activity and ees. The results of alcohol and solvent selection revealed that 1-isooctanol and isooctane were the best substrate and reaction medium, respectively, because of the highest enzyme activity and ees. Compared with the control, conformational studies via FT-IR indicate that the variations of CRL7's secondary structure elements are probably responsible for the differences of enzyme activity and ees in the organic solvents and ionic liquids. Moreover, the effects of reaction parameters, such as molar ratio, water content, temperature, and reaction time, in the selected reaction medium, were also examined.
\end{abstract}

\section{Introduction}

Recently, the enzyme-catalyzed biotransformation in micro-/ nonaqueous solvents has become the exciting field of enzymology [1]. Their usage is especially suitable for the substrates that are unstable or poorly soluble in water [2]. Furthermore, at low moisture content, many water-dependent side reactions can be effectively suppressed [3]. However, the activity and stability of enzymes do not always match the requirement of reactions in micro-/nonaqueous medium. Klibanov reported that the activity and stability of lipases in reaction medium are mainly determined by their native structure. Their activity variations in non-aqueous media could mainly be ascribed to the corresponding change of enzyme conformation [4]. Therefore, it is very important to elucidate the correlation between lipase activity and its conformation variation in the reaction media, which would be better for the understanding of enzymatic biotransformation in nonaqueous medium.

In this work, CRL7 was chosen for evaluating the correlation between its structure and catalytic properties, for
CRL7 has been extensively demonstrated to be effective for biotransformation reactions in aqueous and non-aqueous phases owing to its high activity and broad specificity. The yeast $C$. rugosa has a family of functional genes encoding several isoenzymes with closely related sequences named Lip1 to Lip7 [5]. Moreover, a novel lipase gene, lipJ08, was cloned from C. rugosa ATCC14830 in our laboratory [6]. Although CRL7 has been reported to be applied in many fields, such as enrichment of polyunsaturated fatty acids [7], biocatalytic synthesis of phytosterol esters [8], biodiesel synthesis [9], and even resolution of enantiomers [10], the relationship between its enzyme activity, especially enantioselectivity and conformation (secondary structure) variation, in the resolution reaction, has rarely been addressed. In particular, the comparison of enzyme activity/ees in conventional organic solvents and ionic liquids as well as its conformation variation in these media had seldom been studied.

The enantioselective esterification of ibuprofen with short chain alcohol was chosen in this study, as ibuprofen (2-(4isobutylphenyl) propionic acid) is representative of the 2-aryl propionic acid (2-APA) derivative family. The 2-APA class 
of nonsteroidal anti-inflammatory drugs (NSAIDs) is one of the most commercially successful and important classes of analgesic anti-inflammatory drugs in the world [11]. They have an asymmetric carbon in the second position. The anti-inflammatory and analgesic effects of the 2-APA are attributed almost exclusively to the $S$-enantiomer by inhibiting cyclooxygenase system [12]. It has been reported that $(S)$ ibuprofen is 160 -fold more active than its antipode in the synthesis of prostaglandin "in vitro" [13].

Therefore, the main purposes of this work are (1) to investigate the properties of CRL7 with different short chain alcohols and thus select the best acyl donor; (2) to examine the effect of various organic solvents and ionic liquids on the lipase structure and enzyme activity; and (3) to further explore the effects of reaction parameters, such as molar ratio, water content, temperature, and reaction time.

\section{Materials and Methods}

2.1. Materials. Racemic and optically pure ibuprofen was purchased from the National Institute for Food and Drug Control (China). CRL7 was bought from Sigma-Aldrich Co., Ltd (St. Louis, MO, USA). All organic solvents used were obtained commercially from Sinopharm Chemical Reagent Co., Ltd, Shanghai, China. Other reagents were of analytical grade. High-performance liquid chromatography (HPLC) grade organic solvents were got from TEDIA (USA).

2.2. Enzyme Activity Assay. According to the method described by Chen et al. [14], one unit (U) of enzyme activity was defined as the amount of the enzyme which produces $1 \mu \mathrm{mol}$ ibuprofen ester (isooctyl ester or other esters of short chain alcohols) per hour under the assay conditions. The reactions were performed in a $50 \mathrm{~mL}$ stoppered flask at $50^{\circ} \mathrm{C}$ and $200 \mathrm{rpm}$. The assay conditions were used except when otherwise stated in the text. Protein content determination of the lipase was determined by the method of Bradford [15].

2.3. Reaction Procedure. Before usage, both organic solvent and short chain alcohols were dried over $4 \AA$ molecular sieves. $0.01 \mathrm{mmol}$ ibuprofen and $0.1 \mathrm{mmol}$ short chain alcohol were added $5 \mathrm{~mL}$ organic solvent. The reaction mixture reacted in a shaking bath for several hours at $37^{\circ} \mathrm{C}$ and $200 \mathrm{rpm}$. After addition of $100 \mathrm{mg}$ CRL7, the mixture was incubated on a shaker at the same conditions. When the reaction ended, the lipase was then removed by filtration. Samples were taken for analysis by HPLC.

2.4. Analysis and Calculation. The samples were tested by HPLC (Model 2300-525 SSI. Co., Ltd., USA) using a chiral column (Chiralcel OD-H, $4.6 \mathrm{~mm} \times 250 \mathrm{~mm}$, Daicel, Japan) with hexane/2-propanol/trifluoroacetic acid (90:10:0.1, v/v; $1.0 \mathrm{~mL} / \mathrm{min}$ ) as mobile phase and detected at a wavelength of $254 \mathrm{~nm}$ (Model 525 UV Detector SSI. Co., Ltd., USA). The retention times of $(R)$ - and $(S)$-ibuprofen in the column were 7.28 and $8.23 \mathrm{~min}$, respectively.

Enantioselectivity was expressed as $E$ value and was calculated by (1), ees (the enantiomeric excess of the substrate) was calculated by (2), and $C$ was calculated by (3). Consider the following:

$$
\begin{gathered}
E=\frac{\ln [(1-C)(1-\text { ees })]}{\ln [(1-C)(1+\text { ees })]}, \\
\text { ees }=\frac{S-R}{S+R}, \\
C=\frac{S_{0}+R_{0}-(S+R)}{S_{0}+R_{0}},
\end{gathered}
$$

where $C$ represents the conversion ratio of the substrate, ees represents the enantiomeric excess of the substrate, $S_{0}$ and $R_{0}$, respectively, represent the concentrations of the $S$ - and $R$-enantiomers of ibuprofen before reaction, and $S$ and $R$ represent the concentrations of the $S$ - and $R$-enantiomers of ibuprofen after reaction.

2.5. FT-IR Spectroscopy. The CRL7 after being treated with organic solvent and ionic liquids was mixed with $\mathrm{KBr}$ and pressed into pellets, respectively. Then, the above samples were used in the FT-IR measurements. FT-IR measurements were conducted in the region of $400-4000 \mathrm{~cm}^{-1}$. The measurement conditions were $25^{\circ} \mathrm{C}, 20 \mathrm{kHz}$ scan speed, $4 \mathrm{~cm}^{-1}$ spectral resolution, and 128 scan coadditions. The model of equipment was Vertex 70 FT-IR spectrometer (Bruker Optik GMBH, Germany) with the nitrogen-cooled, mercurycadmium-tellurium (MCT) detector. The infrared spectrum of $\mathrm{KBr}$ was subtracted from the infrared spectrum during each measurement. The absorbance spectra at amide I band are between 1700 and $1600 \mathrm{~cm}^{-1}[16,17]$. The predominant absorbance spectra in amide I band were $\alpha$-helix: $1650-$ $1658 \mathrm{~cm}^{-1}, \beta$-sheet: $1620-1640 \mathrm{~cm}^{-1}, \beta$-turn: $1670-1695 \mathrm{~cm}^{-1}$, and random coli: $1640-1650 \mathrm{~cm}^{-1}$, respectively [16]. The secondary structure element content was estimated according to the method described by Yang et al. [18].

\section{Results and Discussion}

3.1. Alcohol Selection for the Enantioselective Esterification of Racemic Ibuprofen. To select the best acyl donor, different alcohols were employed to study the effects of alcohols on the enantioselective esterification of racemic ibuprofen. The results were shown in Figure 2.

As can be seen, almost all alcohols (except for tertalcohols and 1,2-ethanediol) brought about the esterification of ibuprofen. Compared with other primary alcohols, the enzyme activity and ees of straight chain $\mathrm{Cl}-\mathrm{C} 3$ alcohols were markedly lower than those alcohols with middle chain length (C4-C10 alcohols), which indicated that short chain alcohols had negative effect on lipase [19]. The enzyme activity and ees of straight chain $\mathrm{C} 9-\mathrm{C} 10$ alcohols were higher than other C4-C8 alcohols, and C4-C5 alcohols were higher than C6$\mathrm{C} 8$ alcohols. These results indicated that the enzyme activity and ees were profoundly affected by the carbon chain length of alcohols, but the correlation between them was not linear. Among straight chain alcohols, the highest enzyme activity occurred in 1-decanol and its corresponding ees was $0.84 \pm$ 0.03 . However, the enzyme activity and ees of branch chain 
TABLE 1: Effect of alcohols on the enzymatic esterification of ibuprofen*.

\begin{tabular}{lccc}
\hline & Acyl donor & Enzyme activity (U/g) & ees (\%) \\
\hline 1 & Methanol & $41.05 \pm 0.65$ & $24.11 \pm 0.06$ \\
2 & Ethanol & $44.16 \pm 1.20$ & $12.12 \pm 0.03$ \\
3 & 1-Propanol & $33.05 \pm 1.57$ & $16.22 \pm 0.08$ \\
4 & 1-Butanol & $84.50 \pm 1.12$ & $53.42 \pm 0.06$ \\
5 & 1-Pentanol & $95.87 \pm 0.75$ & $66.41 \pm 0.11$ \\
6 & 1-Hexanol & $88.11 \pm 0.93$ & $54.50 \pm 0.12$ \\
7 & 1-Heptanol & $91.29 \pm 0.58$ & $61.01 \pm 0.12$ \\
8 & 1-Octanol & $91.43 \pm 0.56$ & $69.42 \pm 0.07$ \\
9 & 1-Nonanol & $103.9 \pm 3.91$ & $73.91 \pm 0.05$ \\
10 & 1-Decanol & $106.8 \pm 2.56$ & $83.51 \pm 0.03$ \\
11 & Isobutanol & $93.61 \pm 2.56$ & $74.91 \pm 0.05$ \\
12 & Isoamylol & $108.95 \pm 2.56$ & $87.51 \pm 0.06$ \\
13 & Isooctanol & $115.46 \pm 3.12$ & $95.72 \pm 0.04$ \\
14 & tert-Butanol & $\mathrm{ND}$ & $\mathrm{ND}$ \\
15 & tert-Amyl alcohol & $\mathrm{ND}$ & $\mathrm{ND}$ \\
16 & 1,2-Ethanediol & $\mathrm{ND}$ & $\mathrm{ND}$ \\
\hline
\end{tabular}

${ }^{*}$ The reactions were performed at $50^{\circ} \mathrm{C}, 200 \mathrm{rpm}$ for $12 \mathrm{~h} .0 .1 \mathrm{~g}$ CRL7 was added to $5 \mathrm{~mL}$ isooctane containing $0.1 \mathrm{mmol}$ ibuprofen, $1.0 \mathrm{mmol}$ alcohol (from $\mathrm{Cl}$ to $\mathrm{C} 10)$. The data were measured in triplicate and expressed in mean \pm standard deviation (SD); ND indicates not determined.

monohydric alcohols (isobutanol, isoamylol, and isooctanol) were more than those of their corresponding straight chain monohydric alcohols (1-butanol, 1-pentanol, and 1-octanol). Therefore, the enzyme activity and ees are not only dependent on the -OH functional group of alcohols, but also on its location and the structure of the carbon chains. Nevertheless, the esterification of ibuprofen from polyols and tertiary alcohols could not be detected, indicating that the substrate could not react with these alcohols, as the structure of carbon chain of polyols and tertiary alcohols caused more steric hindrance [20]. From Table 1, isooctanol was recommended for the suitable substrate because of its highest enzyme activity and ees.

3.2. Effects of Organic Solvents and Ionic Liquid on the Enzyme Activity and ees of CRL7 in the Resolution of Racemic Ibuprofen. Laane et al. reported that the $\log P$ has the fundamental effect of polarity-hydrophobicity of organic solvents on enzyme-catalyzed reaction [21]. The enzyme activity, stability, and even enantioselectivity in organic solvents are often correlated with the solvent hydrophobicity [20]. The higher activities were found when the $\log P$ was above 2 [22]. As shown in Table 2, the enzyme activity and ees could not be detected in organic solvents with $\log P<2$ (acetonitrile), which indicates that ibuprofen could not react with alcohol in this solvent. When $\log P$ of solvent was beyond 2 , the enzyme activity and ees in alkanes (from cyclohexane to $n$-undecane, $\log P>3)$ were much higher than those in xylene $(\log P=$ $2.5)$, which shows that solvents with higher hydrophobicity are more suitable for CRL7. However, the increase of $\log P$ of solvents did not have the same tendency for the enzyme activity and ees. Among alkanes, the highest enzyme activity
TABLE 2: Effect of solvents on the enzyme activity and ees via esterification of ibuprofen*.

\begin{tabular}{lcccc}
\hline & Solvent & $\log P$ & Enzyme activity $(\mathrm{U} / \mathrm{g})$ & ees $(\%)$ \\
\hline 1 & $n$-Undecane & 6.1 & $82.67 \pm 1.56$ & $49.89 \pm 0.02$ \\
2 & $n$-Decane & 5.6 & $74.55 \pm 1.51$ & $41.57 \pm 0.02$ \\
3 & $n$-Nonane & 5.1 & $64.27 \pm 4.21$ & $35.39 \pm 0.01$ \\
4 & Isooctane & 4.7 & $118.02 \pm 5.65$ & $92.01 \pm 0.01$ \\
5 & $n$-Octane & 4.5 & $79.70 \pm 3.13$ & $43.75 \pm 0.02$ \\
6 & $n$-Heptane & 4.0 & $79.72 \pm 4.15$ & $45.51 \pm 0.01$ \\
7 & $n$-Hexane & 3.5 & $81.24 \pm 6.41$ & $42.38 \pm 0.02$ \\
8 & Cyclohexane & 3.2 & $79.01 \pm 5.65$ & $43.83 \pm 0.01$ \\
9 & Xylene & 2.5 & $23.84 \pm 5.35$ & $8.54 \pm 0.04$ \\
10 & Acetonitrile & -0.33 & $\mathrm{ND}$ & $\mathrm{ND}$ \\
11 & BmimTF2N & & $60.68 \pm 4.64$ & $33.44 \pm 0.01$ \\
12 & BmimPF6 & & $84.95 \pm 3.23$ & $53.96 \pm 0.02$ \\
13 & EmimPF6 & & $96.42 \pm 5.11$ & $65.84 \pm 0.01$ \\
\hline
\end{tabular}

${ }^{*}$ The reactions were performed at $50^{\circ} \mathrm{C}, 200 \mathrm{rpm}$ for $12 \mathrm{~h} .0 .1 \mathrm{~g}$ CRL7 was added to $5 \mathrm{~mL}$ solvent (from $\log P=6.1$ to $\log P=-0.33$ ) containing $0.01 \mathrm{mmol}$ ibuprofen, $1.0 \mathrm{mmol}$ isooctanol. The data were measured in triplicate and expressed in mean \pm standard deviation (SD); ND indicates not determined.

occurred in isooctane, and its corresponding ees was $0.92 \pm$ 0.01 , which was also the highest value. Three different types of ionic liquids were also chosen as solvents. Compared with organic solvents, enzyme activity and ees in BmimPF6 and BmimTF2N were similar to those in $n$-undecane and $n$ nonane. Among ionic liquids, their enzyme activity and ees were not the same, which indicates that the cations and anions have different effects. This could also be proved by the results from Table 2: BmimPF6 and BmimTF2N had the same cation (Bmim) and BmimPF6 and EmimPF6 had the same anion (PF6), but their enzyme activity and ees were not the same. This phenomenon coincides with the result reported by Pan et al. who pointed out that the probable reason was ascribed to the viscosity and hydrophilicity of ionic liquids [23].

3.3. Secondary Structure Analysis of CRL7 by FT-IR Spectroscopy. Conformational structure change of the CRL7 treated with the organic solvents and ionic liquids is probably the reason for the variation of enzyme activity and ees [24]. To verify this hypothesis, CRL7 was incubated in organic solvents and ionic liquids with the same conditions as described above in Section 2.2. The organic solvents and ionic liquids were then removed under reduced pressure by a vacuum pump and the residual enzyme was dried according to the method described by Pan et al. [23]. Then, FT-IR experiments were conducted to analyze the secondary structure variation with the conditions described in Section 2.5, and the variations of secondary structure elements were shown in Table 3.

As can be seen in Table 3, the secondary structure element content of CRL7 without treatment of organic solvent and ionic liquids was $\alpha$-helix: $43.46 \%$, $\beta$-sheet: $26.91 \%, \beta$-turn: $11.83 \%$, and random coli: $17.79 \%$, respectively. After being treated with organic solvents, the corresponding contents were $\alpha$-helix: $21.03-40.88 \%$, $\beta$-sheet: $22.22-46.43 \%, \beta$-turn: 11.93-21.57\%, and random coli: 17.94-25.83\%. Compared with 
TABLE 3: Quantitative estimation of the secondary structure elements of the treated CRL7 calculated by FT-IR spectroscopy measurement* .

\begin{tabular}{llllc}
\hline Solvent & $\alpha$-Helix (\%) & $\beta$-Sheet (\%) & $\beta$-Turn (\%) & Random coil (\%) \\
\hline Control & $43.46 \pm 0.02$ & $26.91 \pm 0.02$ & $11.83 \pm 0.03$ & $17.79 \pm 0.04$ \\
$n$-Undecane & $33.39 \pm 0.02$ & $27.10 \pm 0.09$ & $21.57 \pm 0.02$ & $17.94 \pm 0.02$ \\
$n$-Decane & $21.38 \pm 0.21$ & $46.04 \pm 0.11$ & $11.93 \pm 0.06$ & $20.65 \pm 0.15$ \\
$n$-Nonane & $21.03 \pm 0.03$ & $46.43 \pm 0.03$ & $12.76 \pm 0.13$ & $13.53 \pm 0.06$ \\
Isooctane & $39.03 \pm 0.12$ & $37.61 \pm 0.04$ & $13.75 \pm 0.12$ & $18.72 \pm 0.05$ \\
$n$-Octane & $23.62 \pm 0.06$ & $40.95 \pm 0.16$ & $13.04 \pm 0.14$ & $21.68 \pm 0.08$ \\
$n$-Heptane & $22.23 \pm 0.13$ & $44.55 \pm 0.15$ & $13.81 \pm 0.09$ & $20.18 \pm 0.06$ \\
$n$-Hexane & $38.53 \pm 0.09$ & $27.83 \pm 0.13$ & $12.82 \pm 0.04$ & $19.83 \pm 0.10$ \\
Cyclohexane & $21.17 \pm 0.12$ & $45.74 \pm 0.12$ & $14.51 \pm 0.10$ & $20.26 \pm 0.10$ \\
Xylene & $37.43 \pm 0.05$ & $22.22 \pm 0.12$ & $21.58 \pm 0.11$ & $25.83 \pm 0.15$ \\
Acetonitrile & $40.88 \pm 0.12$ & $24.94 \pm 0.04$ & $19.43 \pm 0.12$ & $19.59 \pm 0.02$ \\
BmimTF2N & $24.27 \pm 0.05$ & $25.62 \pm 0.10$ & $16.81 \pm 0.13$ & $28.52 \pm 0.11$ \\
BmimPF6 & $24.90 \pm 0.04$ & $14.39 \pm 0.09$ & & $41.28 \pm 0.14$ \\
EmimPF6 & $32.33 \pm 0.10$ & $23.09 \pm 0.08$ & $27.77 \pm 0.12$ \\
\hline
\end{tabular}

* The lipase without treatment of organic solvent and ionic liquids was set as control.

The data were measured in triplicate and expressed in mean \pm standard deviation (SD).

the control, on the whole, CRL7 exhibited a decrease in $\alpha$ helix and an increase in $\beta$-sheet, $\beta$-turn, and random coil (except for xylene and acetonitrile whose $\beta$-sheet decreased). The decrease tendency in $\alpha$-helix coincides with the conclusion of Pan et al. [23], who had reported that the enzyme activity increased with the decrease of $\alpha$-helix content, which was ascribed to the influence of $\alpha$-helix on the "open" tendency of active site of the lipase. The open tendency of active site would make it easier for the substrate to access it. Moreover, $\alpha$-helix content treated by isooctane was the highest among organic solvents (except for acetonitrile), whose ees and enzyme activity were also the highest (see Table 1). As for $\beta$-Sheet, compared with the control, its content increased in short chain alkanes with relatively higher $\log P$ (from $n$ undecane to cyclohexane) and decreased in xylene $(\log P=$ 2.5) acetonitrile $(\log P=-0.33)$. Moreover, as shown in Table 1, the enzyme activity and ees in the short chain alkanes were much higher than those in xylene and acetonitrile (whose $\beta$-sheet decreased in Table 3 ). From the relationship between CRL7 activity and the corresponding $\beta$-sheet content, it was maybe speculated that the increase in $\beta$-sheet content of secondary structure in the solvents was responsible for their activity enhancement.

Compared with the control, random coil content decreased in all solvents, which had the opposite tendency of $\alpha$-helix. The reason for the increased tendency was attributed to a certain amount of $\alpha$-helix being converted into random coils. Zheng et al. reported that the conformational transition of lipase could lead to the decrease in $\alpha$-helix and the increase in random coil [25].

The change of secondary structure element contents in ionic liquids was similar to the tendency of those in organic solvents: decrease in $\alpha$-helix and increase in $\beta$-turn and random coil. Moreover, the variation ranges of $\alpha$-helix and $\beta$-turn contents were not exceeding those in the short chain alkanes, which was in accordance with the variation trends of enzyme activity and ees. Gu and Li had pointed out that the activity variation of lipase in ionic liquids was probably related to its conformation change caused by different properties of ionic liquids, such as polarity, hydrophobicity, hydrogen bonding, basicity, and viscosity [26].

\subsection{Effect of Reaction Parameters}

3.4.1. Effect of Molar Ratio. According to the results from Table 1, isooctanol was chosen as acyl acceptor. $1 \mathrm{~mol}$ of isooctanol is required to react with $1 \mathrm{~mol}$ of ibuprofen. In practice, an excess amount of alcohol can drive the reversible reaction to the right side so as to produce more esters. As shown in Figure 1, both enzyme activity and ees had the same increasing tendency with the growth of molar ratio. For enzyme activity, its highest value was obtained at molar ratio of $8: 1$. For ees, the highest value occurred at molar ratio of $10: 1$. Beyond the highest value, both enzyme activity and ees showed a decrease tendency with further increase of molar ratio.

3.4.2. Effect of Water Content. Water plays a critical role in the structure and function of enzymes because of its influence on enzymes' active conformation. As can be seen in Figure 2, enzyme activity and ees show a decreasing tendency. Herbst et al. reported that protein destruction might take place when clusters of water on protein surface agglomerated into large clusters. These clusters caused structural changes by promoting the formation of enzyme agglomeration up to denaturation [22]. Therefore, if water layer is sufficiently large, the transfer of acyl group to the active site will be prevented, which leads to a decrease in conversion [27].

3.4.3. Effect of Temperature. For analysis of temperature influence, reactions were carried out within the range from 20 to $70^{\circ} \mathrm{C}$. As shown in Figure 3, when temperature was 


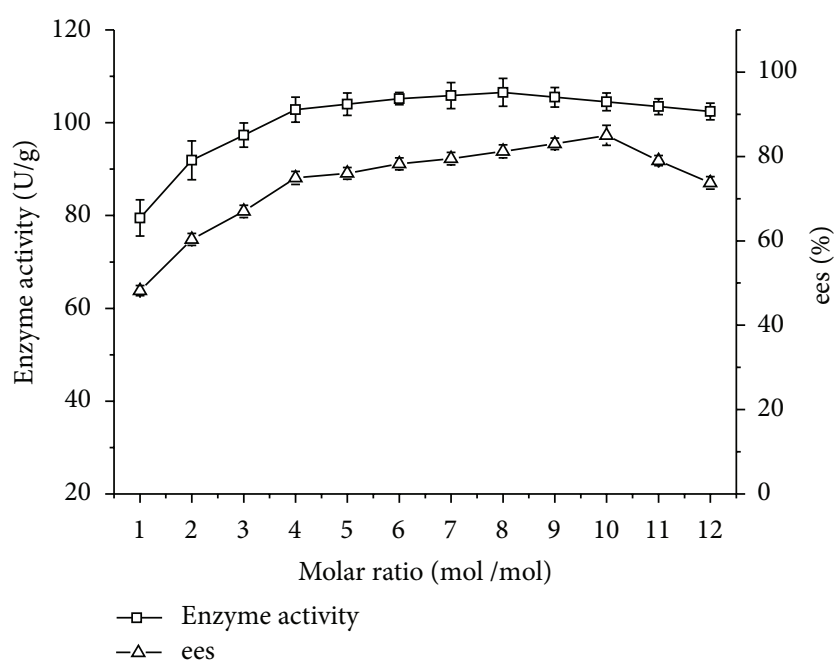

FIGURE 1: Effect of substrate molar ratio on enzyme activity/ees of CRL7. Reaction condition: $0.1 \mathrm{~g}$ CRL7 was added to $5 \mathrm{~mL}$ isooctane containing $0.1 \mathrm{mmol}$ ibuprofen, $1-12 \mathrm{mmol}$ isooctanol. The reactions were performed at $50^{\circ} \mathrm{C}, 200 \mathrm{rpm}$ for $24 \mathrm{~h}$. The data were measured in triplicate and vertical bars represent standard deviation.

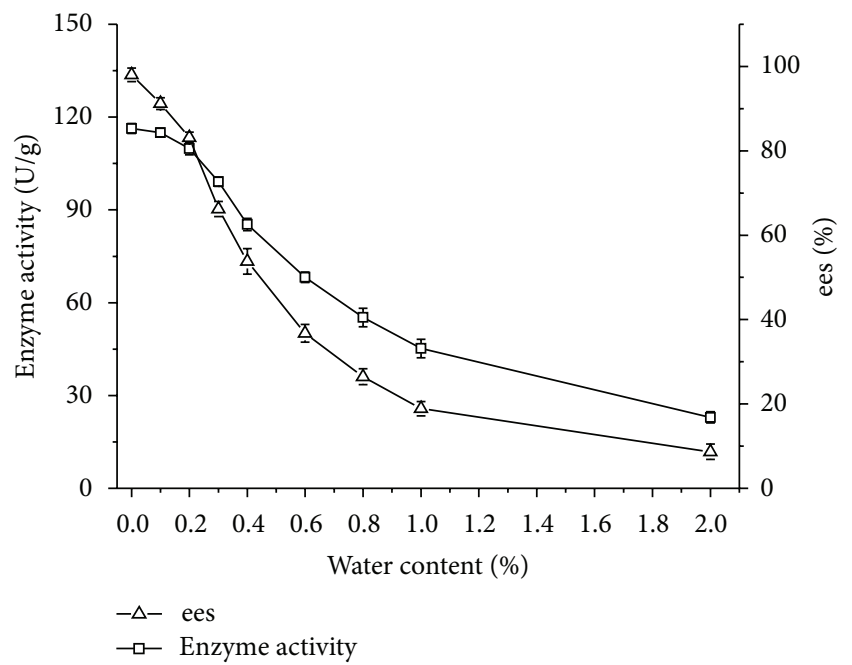

FIGURE 2: Effect of water content on enzyme activity/ees of CRL7. Reaction condition: $0.1 \mathrm{~g}$ CRL7 was added to $5 \mathrm{~mL}$ isooctane containing $0.1 \mathrm{mmol}$ ibuprofen, $1 \mathrm{mmol}$ isooctanol. The reactions were performed at $50^{\circ} \mathrm{C}, 200 \mathrm{rpm}$ for $24 \mathrm{~h}$. The data were measured in triplicate and vertical bars represent standard deviation.

below $50^{\circ} \mathrm{C}$, enzyme activity and ees showed an increasing tendency with the increase of temperature. This increase can be explained by temperature dependency of the reaction rate. When temperature was beyond $50^{\circ} \mathrm{C}$, the further increase of temperature would result in a decrease in both enzyme activity and ees, indicating that too much higher temperature had negative effect on enzyme activity and ees.

3.4.4. Effect of Reaction Time. As shown in Figure 4, when reaction time was more than $20 \mathrm{~h}$, the conversion and ees were close to $50 \%$ and $100 \%$, respectively, and

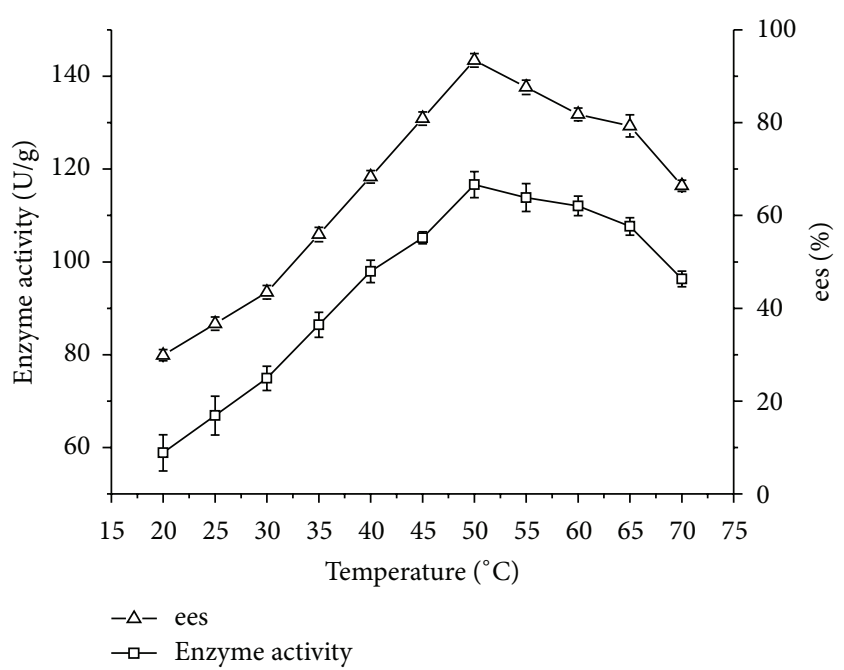

FIGURE 3: Effect of temperature on enzyme activity/ees of CRL7. Reaction condition: $0.1 \mathrm{~g}$ CRL7 was added to $5 \mathrm{~mL}$ isooctane containing $0.1 \mathrm{mmol}$ ibuprofen, $1 \mathrm{mmol}$ isooctanol. The reactions were performed at different temperatures, $200 \mathrm{rpm}$ for $24 \mathrm{~h}$. The data were measured in triplicate and vertical bars represent standard deviation.

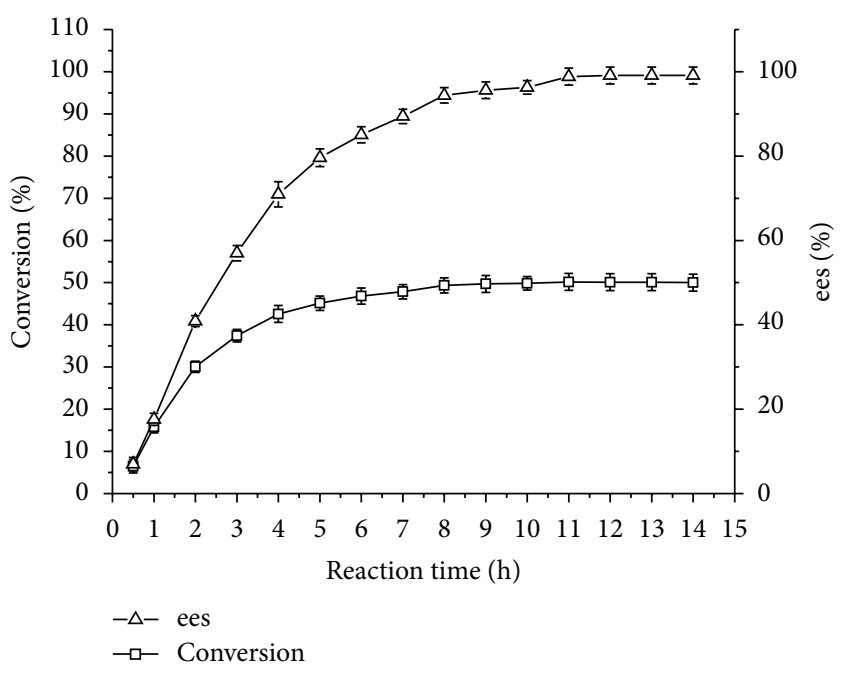

Figure 4: Effect of reaction time on conversion/ees of CRL7. Reaction condition: $0.1 \mathrm{~g}$ CRL7 was added to $5 \mathrm{~mL}$ isooctane containing $0.1 \mathrm{mmol}$ ibuprofen, $1 \mathrm{mmol}$ isooctanol. The reactions were performed at $50^{\circ} \mathrm{C}, 200 \mathrm{rpm}$ for different reaction times. The data were measured in triplicate and vertical bars represent standard deviation.

the corresponding $E$ value was more than 200. It indicated that all of (S)-ibuprofen had nearly been converted into $(S)$-ibuprofen isooctyl ester, while $(R)$-ibuprofen remained unchanged in the reaction mixture, which also further proved that CRL7 had a good preference for $(S)$-ibuprofen. Moreover, it had been reported that the unreacted ibuprofen and the corresponding ester could be quantitatively separated by bulb-to-bulb distillation because of the molecular weight difference between them [28]. 


\section{Conclusion}

In this study, according to the methods of substrate engineering and medium engineering, it could be stated that alcohols and solvents had great effect on the enantioselective performance of CRL7. The effects of carbon chain length of alcohols were larger than solvents on enzyme activity and enantioselectivity. 1-Isooctanol and isooctane were recommended for the best substrate and best reaction medium, respectively, because of the highest enantioselectivity. The investigation of reaction parameters (such as molar ratio, water content, temperature, and reaction time) showed that CRL7 had a good preference for $(S)$-ibuprofen and a great prospect in industrial application.

\section{Conflict of Interests}

The authors declare that there is no conflict of interests.

\section{Authors' Contribution}

Xiang Li and Shuangshuang Huang contributed equally to this work.

\section{Acknowledgments}

This work is financially supported by the National Natural Science Foundation of China (nos. 31070089, 31170078, and J1103514), the National High Technology Research and Development Program of China (2011AA02A204), the Innovation Foundation of Shenzhen Government (JCYJ20120831111657864), and the Fundamental Research Funds for the Central Universities HUST (no. 2172012SHYJ004). Many thanks are indebted to Ms. Hong Chen and Xiaoman Gu (Analytical and Testing Center of HUST) for their valuable assistance in FT-IR spectroscopy measurement.

\section{References}

[1] P. V. Iyer and L. Ananthanarayan, "Enzyme stability and stabilization-aqueous and non-aqueous environment," Process Biochemistry, vol. 43, no. 10, pp. 1019-1032, 2008.

[2] A. Klibanov, "Why are enzymes less active in organic solvents than in water?" Trends in Biotechnology, vol. 15, no. 3, pp. 97-101, 1997.

[3] B. Hernández-Rodríguez, J. Córdova, E. Bárzana, and E. FavelaTorres, "Effects of organic solvents on activity and stability of lipases produced by thermotolerant fungi in solid-state fermentation," Journal of Molecular Catalysis B, vol. 61, no. 3-4, pp. 136-142, 2009.

[4] A. M. Klibanov, "Improving enzymes by using them in organic solvents," Nature, vol. 409, no. 6817, pp. 241-246, 2001.

[5] Y. Liu, D. Chen Y Yan, and Y. Yan, "Effect of ionic liquids, organic solvents and supercritical $\mathrm{CO}_{2}$ pretreatment on the conformation and catalytic properties of Candida rugosa lipase," Journal of Molecular Catalysis B, vol. 90, pp. 123-127, 2013.

[6] L. Xu, X. Jiang, J. Yang, Y. Liu, and Y. Yan, "Cloning of a novel lipase gene, lipJ08, from Candida rugosa and expression in Pichia pastoris by codon optimization," Biotechnology Letters, vol. 32, no. 2, pp. 269-276, 2010.
[7] D. Kahveci and X. Xu, "Repeated hydrolysis process is effective for enrichment of omega 3 polyunsaturated fatty acids in salmon oil by Candida rugosa lipase," Food Chemistry, vol. 129, no. 4, pp. 1552-1558, 2011.

[8] M.-M. Zheng, Y. Lu, L. Dong et al., "Immobilization of Candida rugosa lipase on hydrophobic/strong cation-exchange functional silica particles for biocatalytic synthesis of phytosterol esters," Bioresource Technology, vol. 115, pp. 141-146, 2011.

[9] J. H. Lee, S. B. Kim, S. W. Kang et al., "Biodiesel production by a mixture of Candida rugosa and Rhizopus oryzae lipases using a supercritical carbon dioxide process," Bioresource Technology, vol. 102, no. 2, pp. 2105-2108, 2011.

[10] T. Siódmiak, M. Ziegler-Borowska, and M. P. Marszałł, "Lipaseimmobilized magnetic chitosan nanoparticles for kinetic resolution of $(R, S)$-ibuprofen," Journal of Molecular Catalysis B, vol. 94, pp. 7-14, 2013.

[11] A. Ghanem, M. N. Aboul-Enein, A. El-Azzouny, and M. F. ElBehairy, "Lipase-mediated enantioselective kinetic resolution of racemic acidic drugs in non-standard organic solvents: direct chiral liquid chromatography monitoring and accurate determination of the enantiomeric excesses," Journal of Chromatography A, vol. 1217, no. 7, pp. 1063-1074, 2010.

[12] G. Duan, C. B. Ching, E. Lim, and C. H. Ang, "Kinetic study of enantioselective esterification of ketoprofen with n-propanol catalysed by an lipase in an organic medium," Biotechnology Letters, vol. 19, no. 11, pp. 1051-1055, 1997.

[13] Y. Liu, F. Wang, and T. Tan, "Effects of alcohol and solvent on the performance of lipase from Candida sp. in enantioselective esterification of racemic ibuprofen," Journal of Molecular Catalysis B, vol. 56, no. 2-3, pp. 126-130, 2009.

[14] C.-S. Chen, Y. Fujimoto, G. Girdaukas, and C. J. Sih, "Quantitative analyses of biochemical kinetic resolutions of enantiomers," Journal of the American Chemical Society, vol. 104, no. 25, pp. 7294-7299, 1982.

[15] M. M. Bradford, "A rapid and sensitive method for the quantitation of microgram quantities of protein utilizing the principle of protein dye binding," Analytical Biochemistry, vol. 72, no. 1-2, pp. 248-254, 1976.

[16] M. Carbonaro and A. Nucara, "Secondary structure of food proteins by Fourier transform spectroscopy in the mid-infrared region," Amino Acids, vol. 38, no. 3, pp. 679-690, 2010.

[17] R. Pribic, I. H. M. Vanstokkum, D. Chapman, P. I. Haris, and M. Bloemendal, "Protein secondary structure from Fourier transform infrared and/or circular dichroism spectra," Analytical Biochemistry, vol. 214, no. 2, pp. 366-378, 1993.

[18] C. Yang, F. Wang, D. Lan, C. Whiteley, B. Yang, and Y. Wang, "Effects of organic solvents on activity and conformation of recombinant Candida antarctica lipase A produced by Pichia pastoris," Process Biochemistry, vol. 47, no. 3, pp. 533-537, 2012.

[19] Y. Liu, H. Tan, X. Zhang, Y. Yan, and B. H. Hameed, "Effect of monohydric alcohols on enzymatic transesterification for biodiesel production," Chemical Engineering Journal, vol. 157, no. 1, pp. 223-229, 2010.

[20] X. Li, T. Liu, L. Xu, X. Gui, F. Su, and Y. Yan, "Resolution of racemic ketoprofen in organic solvents by lipase from Burkholderia cepacia G63," Biotechnology and Bioprocess Engineering, vol. 17, no. 6, pp. 1147-1155, 2012.

[21] C. Laane, S. Boeren, K. Vos, and C. Veeger, "Rules for optimization of biocatalysis in organic solvents," Biotechnology and Bioengineering, vol. 102, no. 1, pp. 1-8, 2009. 
[22] D. Herbst, S. Peper, and B. Niemeyer, "Enzyme catalysis in organic solvents: influence of water content, solvent composition and temperature on Candida rugosa lipase catalyzed transesterification," Journal of Biotechnology, vol. 162, no. 4, pp. 398-403, 2012.

[23] S. Pan, X. Liu, Y. Xie et al., "Esterification activity and conformation studies of Burkholderia cepacia lipase in conventional organic solvents, ionic liquids and their co-solvent mixture media," Bioresource Technology, vol. 101, no. 24, pp. 9822-9824, 2010.

[24] Y. Liu, D. Chen, and Y. Yan, "Effect of ionic liquids, organic solvents and supercritical $\mathrm{CO}_{2}$ pretreatment on the conformation and catalytic properties of Candida rugosa lipase," Journal of Molecular Catalysis B, vol. 90, pp. 123-127, 2013.

[25] J. Zheng, L. Xu, Y. Liu, X. Zhang, and Y. Yan, "Lipase-coated $\mathrm{K}_{2} \mathrm{SO}_{4}$ micro-crystals: preparation, characterization, and application in biodiesel production using various oil feedstocks," Bioresource Technology, vol. 110, pp. 224-231, 2012.

[26] Y. Gu and G. Li, "Ionic liquids-based catalysis with solids: state of the art," Advanced Synthesis and Catalysis, vol. 351, no. 6, pp. 817-847, 2009.

[27] P. Domínguez de María, J. M. . Sánchez-Montero, J. V. . Sinisterra, and A. R. . Alcántara, "Understanding Candida rugosa lipases: an overview," Biotechnology Advances, vol. 24, no. 2, pp. 180-196, 2006.

[28] D. Chávez-Flores and J. M. Salvador, "Commercially viable resolution of ibuprofen," Biotechnology Journal, vol. 4, no. 8, pp. 1222-1224, 2009. 

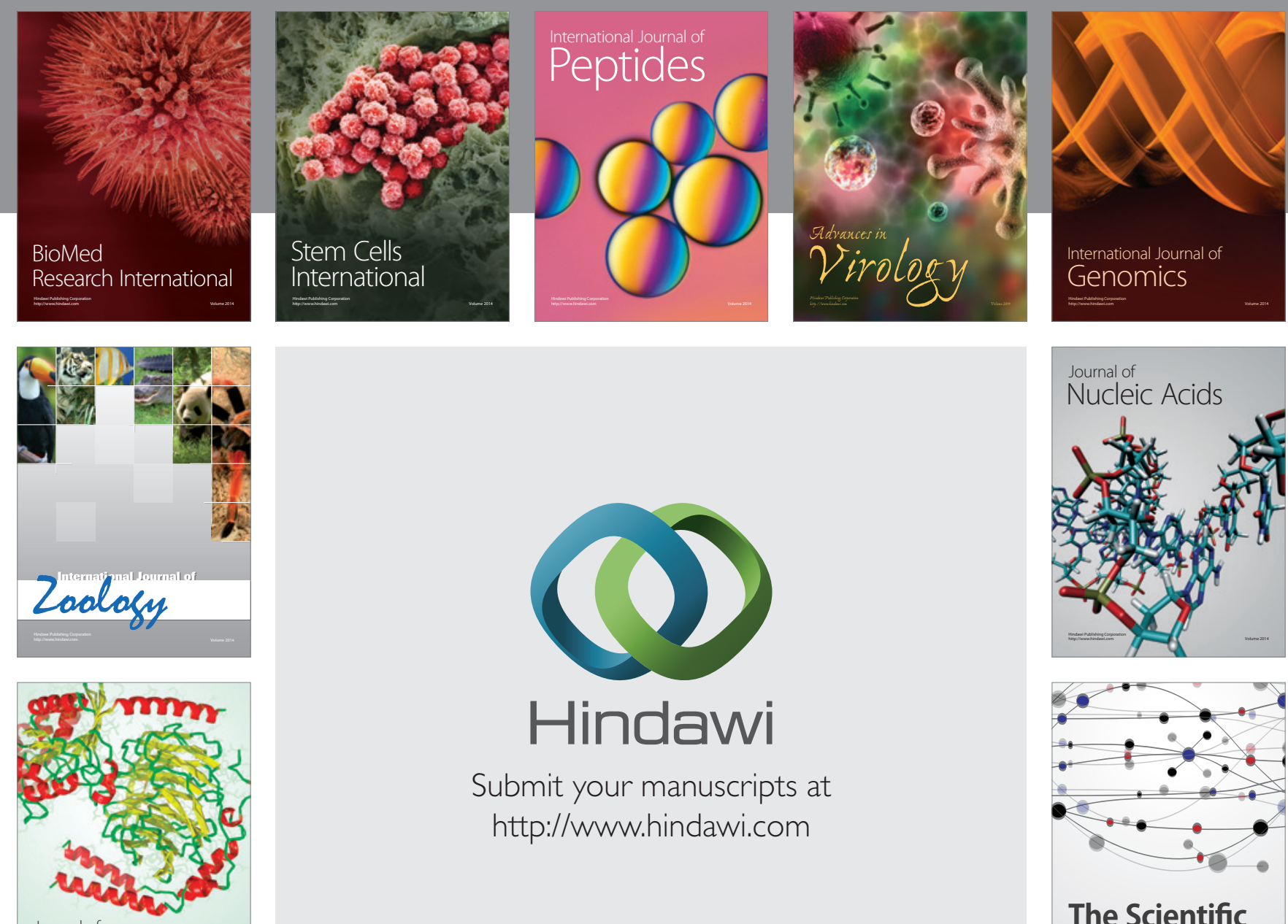

Submit your manuscripts at

http://www.hindawi.com

Journal of
Signal Transduction
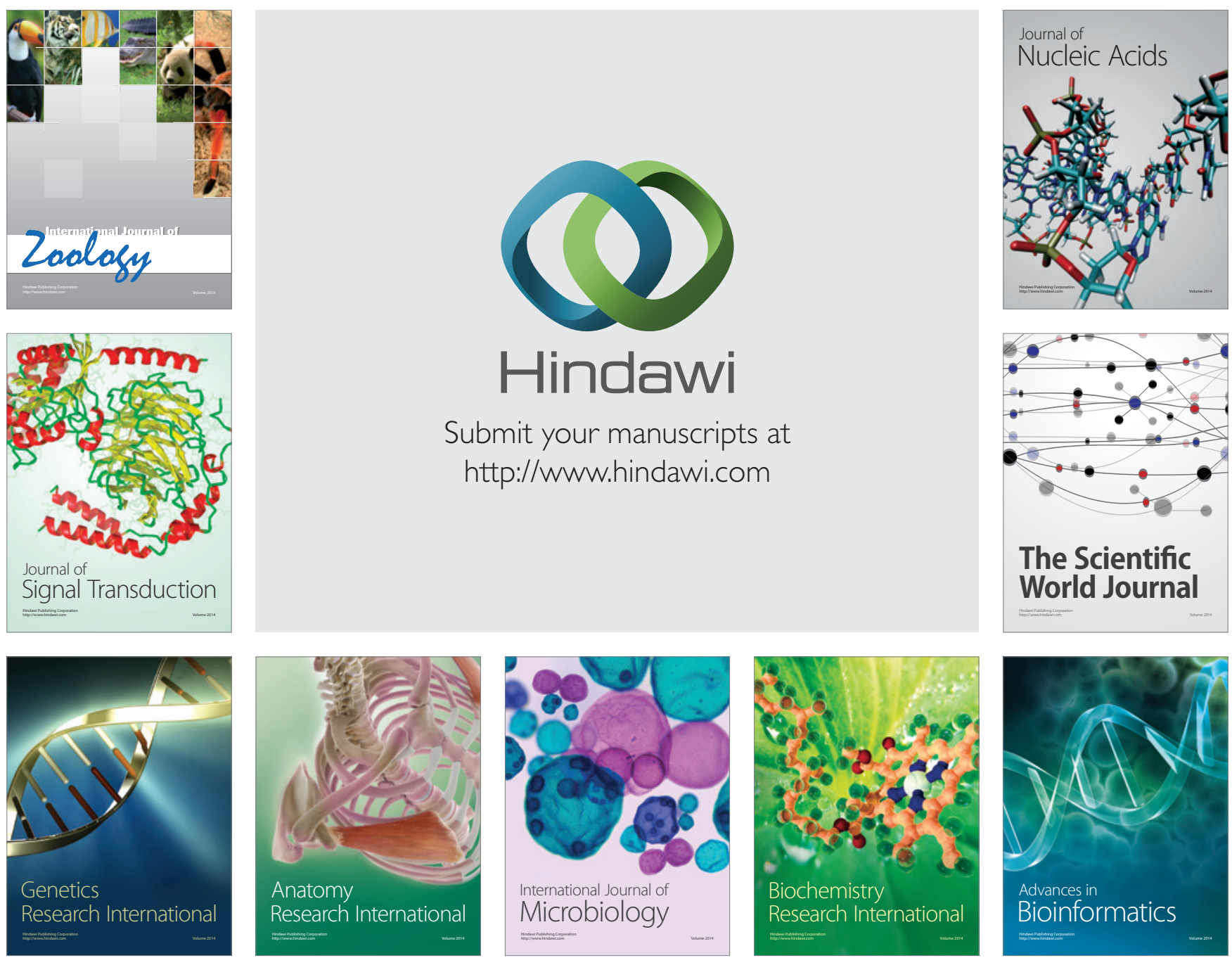

The Scientific World Journal
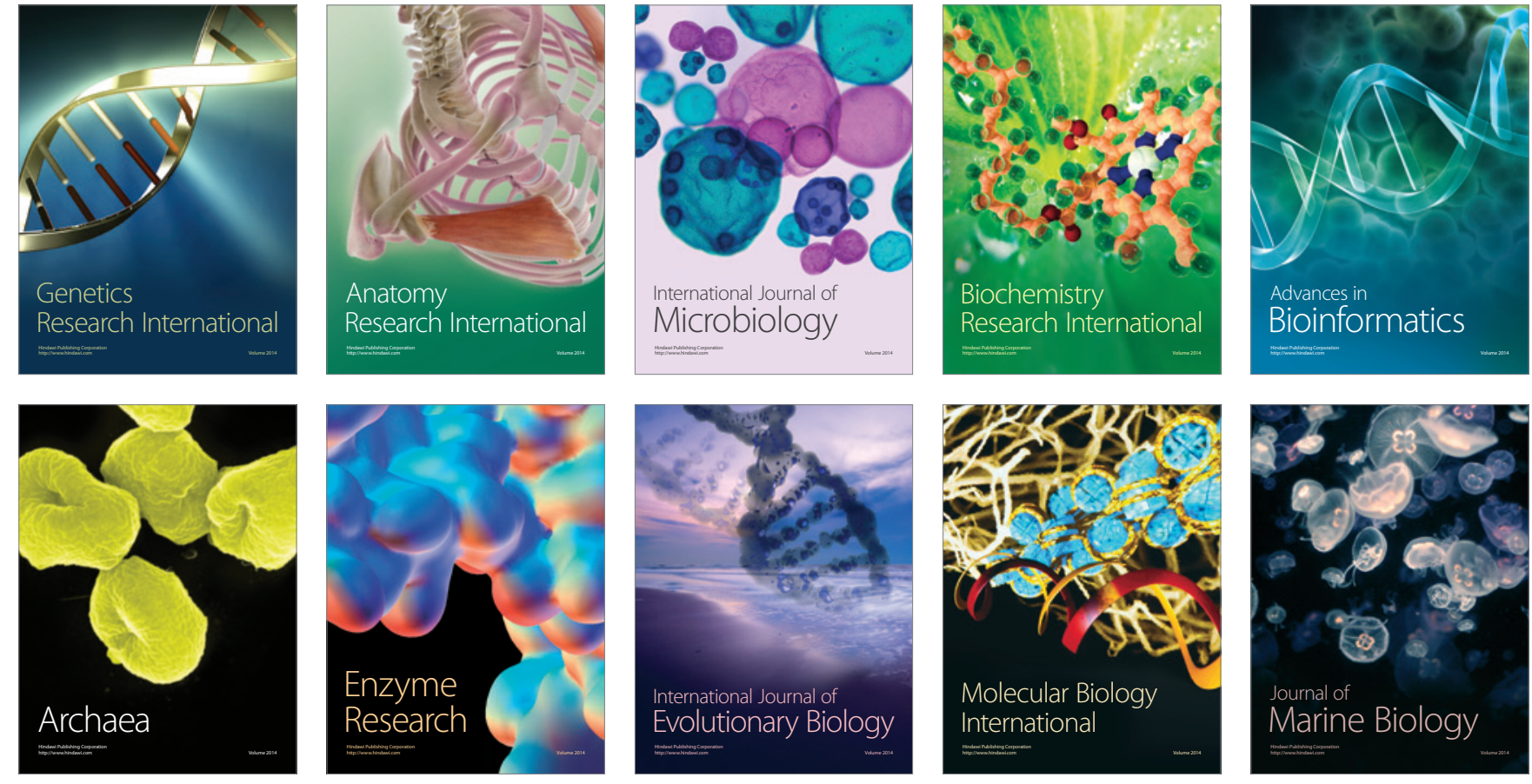